\title{
Early response to COVID-19 in the Philippines
}

\author{
Arianna Maever L. Amit, $a, b$ Veincent Christian F. Pepito ${ }^{a, b}$ and Manuel M. Dayritb \\ Correspondence to Arianna Maever L. (email: alamit@up.edu.ph)
}

Low- and middle-income countries (LMICs) with weak health systems are especially vulnerable during the COVID-19 pandemic. In this paper, we describe the challenges and early response of the Philippine Government, focusing on travel restrictions, community interventions, risk communication and testing, from 30 January 2020 when the first case was reported, to 21 March 2020. Our narrative provides a better understanding of the specific limitations of the Philippines and other LMICs, which could serve as basis for future action to improve national strategies for current and future public health outbreaks and emergencies.

\section{THE PHILIPPINE HEALTH SYSTEM AND THE THREAT OF PUBLIC HEALTH EMER- GENCIES}

$\mathrm{D}$ espite improvements during the past decade, the Philippines continues to face challenges in responding to public health emergencies because of poorly distributed resources and capacity. The Philippines has 10 hospital beds and six physicians per 10000 people., ${ }^{1,2}$ and only about 2335 critical care beds nationwide. ${ }^{3}$ The available resources are concentrated in urban areas, and rural areas have only one physician for populations up to 20000 people and only one bed for a population of $1000 .{ }^{4}$ Disease surveillance capacity is also unevenly distributed among regions and provinces. The primary care system comprises health centres and community health workers, but these are generally ill-equipped and poorly resourced, with limited surge capacity, as evidenced by lack of laboratory testing capacity, limited equipment and medical supplies, and lack of personal protective equipment for health workers in both primary care units and hospitals. ${ }^{5}$ Local government disaster preparedness plans are designed for natural disasters and not for epidemics.

Inadequate, poorly distributed resources and capacity nationally and subnationally have made it difficult to respond adequately to public health emergencies in the past, as in the case of typhoon Haiyan in $2013 .^{6}$ The typhoon affected 13.3 million people, overwhelming the Government's capacity to mobilize human and financial resources rapidly to affected areas. ${ }^{7}$ Failure to deliver basic needs and health services resulted in disease outbreaks, including a community outbreak of gastroenteritis. ${ }^{8}$ Access to care has improved in recent years due to an increase in the number of private hospital beds; ${ }^{5}$ however, improvements in private sector facilities mainly benefit people who can afford them, in both urban and rural areas.

In this paper, we describe the challenges and early response of the Philippine Government, focusing on travel restrictions, community interventions, risk communication and testing, from 30 January 2020 when the first case was reported, to 21 March 2020.

\section{EARLY RESPONSE TO COVID-19}

\section{Travel restrictions}

Travel restrictions in the Philippines were imposed as early as 28 January, before the first confirmed case was reported on 30 January (Fig. 1a). ${ }^{9}$ After the first few COVID-19 cases and deaths, the Government conducted contact tracing and imposed additional travel restrictions, ${ }^{10}$ with arrivals from restricted countries subject to 14-day quarantine and testing. While

\footnotetext{
College of Medicine, University of the Philippines Manila, Manila, Philippines. 
Fig. 1a. New cases of COVID-19 in the Philippines, 30 January-21 March 2020

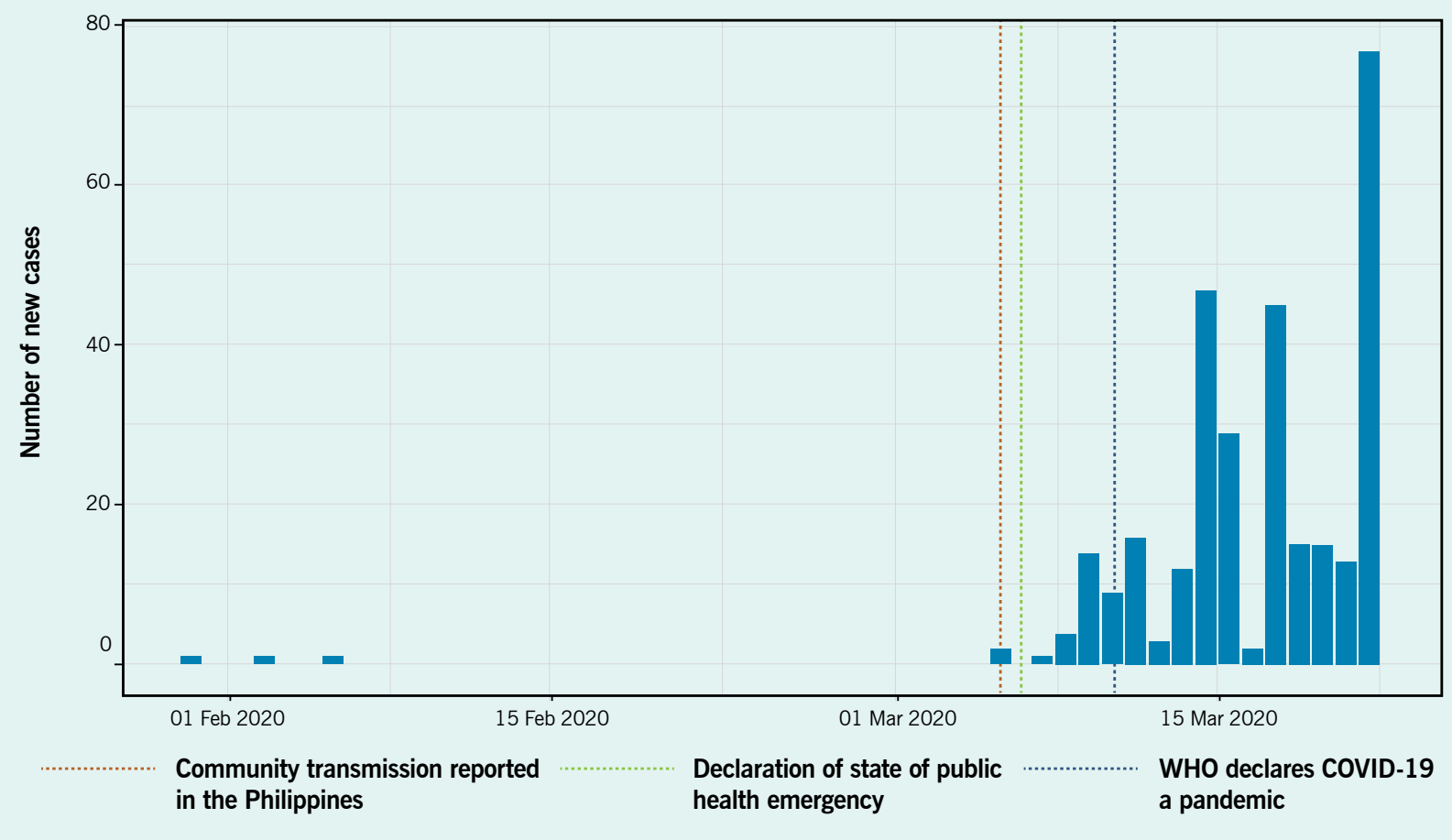

Fig. 1b. Timeline of key events and developments in the Philippines, 30 January-21 March 2020

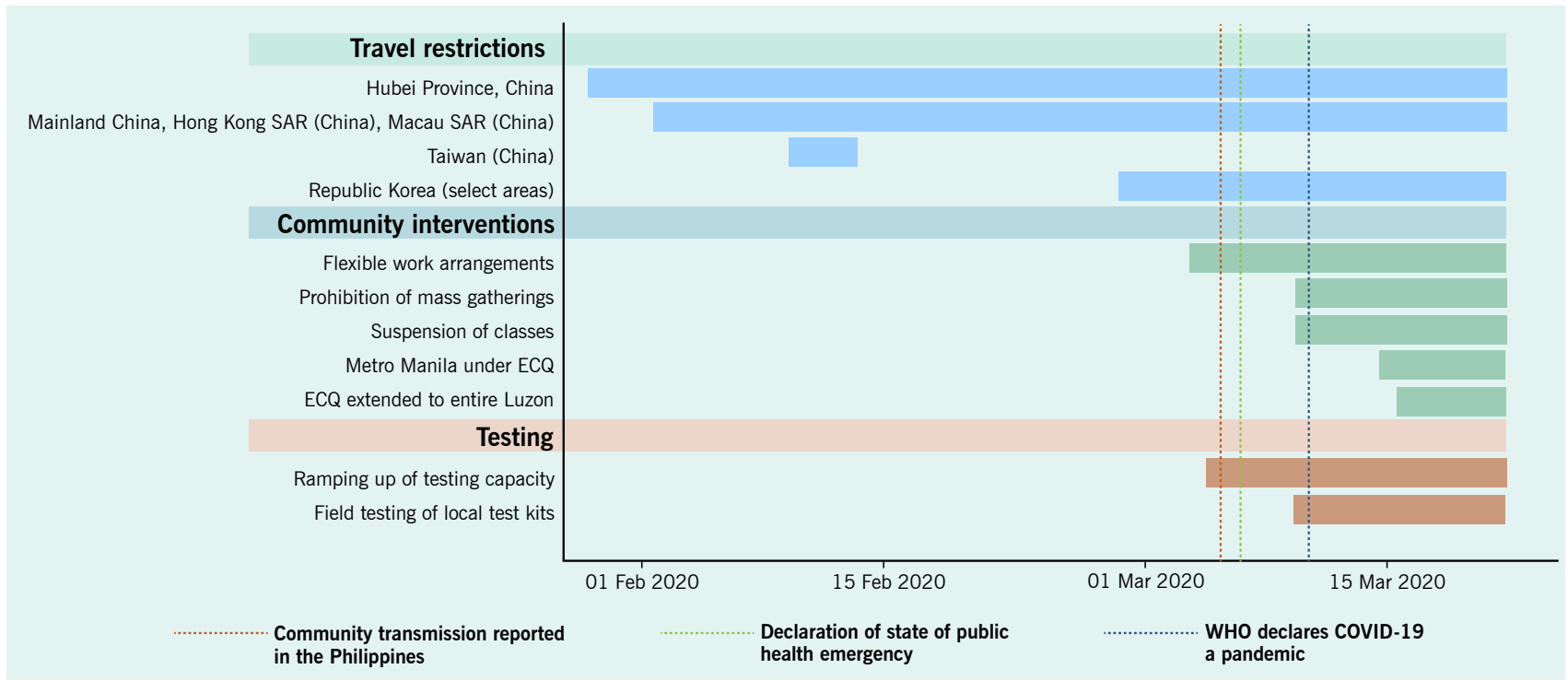

travel restrictions in the early phase of the COVID-19 response prevented spread of the disease by potentially infected people, travellers from countries not on the list of restricted countries were not subject to the same screening and quarantine protocols. The restrictions were successful in delaying the spread of the disease only briefly, as the number of confirmed cases increased in the weeks that followed. ${ }^{11}$ Fig. $1 \mathrm{~b}$ shows all interventions, including travel restrictions undertaken before 6 March, when the Government declared the occurrence of community spread, and after 11 March, when WHO declared COVID-19 a pandemic. 
Fig. 2. Provinces placed under enhanced community quarantine (ECQ). (2a) The Government declared ECQ in Metro Manila effective 15 March 2020; (2b) The Government declared ECQ on the entire island of Luzon effective 17 March 2020.
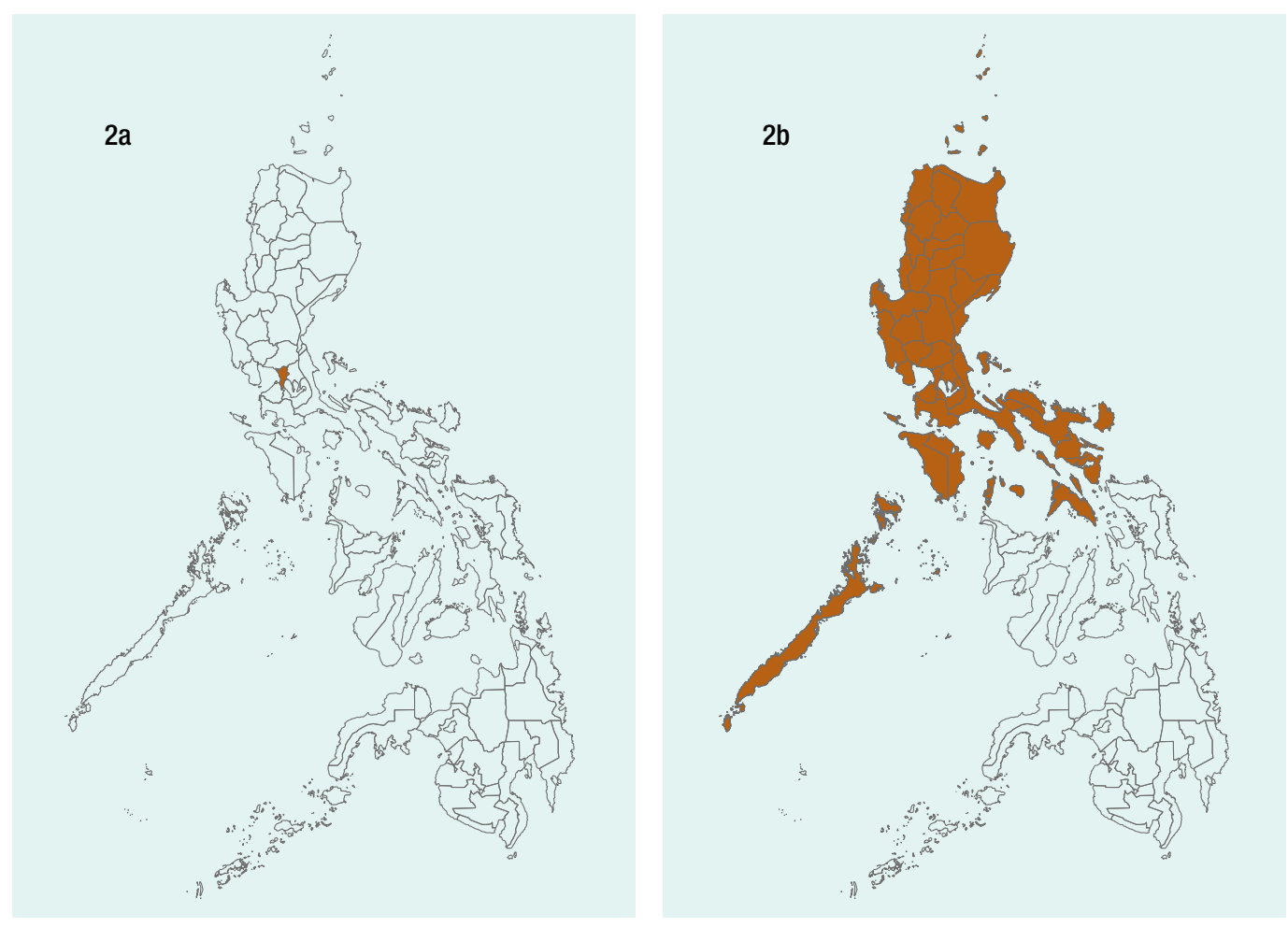

\section{Community interventions}

The Government declared "enhanced community quarantine" (ECQ) for Metro Manila between 15 March and 14 April (Fig. 2a), which was subsequently extended to the whole island of Luzon (Fig. 2b). The quarantine consisted of: strict home quarantine in all households, physical distancing, suspension of classes and introduction of work from home, closure of public transport and non-essential business establishments, prohibition of mass gatherings and non-essential public events, regulation of the provision of food and essential health services, curfews and bans on sale of liquor and a heightened presence of uniformed personnel to enforce the quarantine procedures. ${ }^{12} \mathrm{ECQ}$ - an unprecedented move in the country's history - was modelled on the lockdown in Hubei, China, which was reported to have slowed disease transmission. ${ }^{13}$ Region-wide disease control interventions, such as quarantining of the entire Luzon island, were challenging to implement because of their scale and social and economic impacts, but they were deemed necessary to "flatten the curve" so that health systems were not overwhelmed. ${ }^{14}$ While the lockdown implemented by the Government applied only to the island of Luzon, local governments in other parts of the country followed this example and also locked down. The ECQ gave the country the opportunity to mobilize resources and organize its pandemic response, which was especially important in a country with poorly distributed, scarce resources and capacity.

\section{Risk communication}

The Government strengthened and implemented national risk communication plans to provide information on the new disease. The Government conducted daily press briefings, sponsored health-related television and Internet advertisements and circulated infographics on social media. Misinformation and conspiracy theories about COVID-19 were nevertheless a challenge for a population that spends more than 10 hours a day on the Internet. ${ }^{15,16}$ These spread quickly and became increasingly difficult to correct. Furthermore, the Government's messages did not reach all households, despite access 
to health services and information, resulting in limited knowledge of preventive practices, except for handwashing. ${ }^{17}$

\section{Testing}

Testing is key to controlling the pandemic but was done on a small scale in the Philippines. As of 19 March, fewer than 1200 individuals had been tested, ${ }^{11}$ as only the Research Institute for Tropical Medicine located in Metro Manila performed tests and assisted subnational reference laboratories in testing. ${ }^{18}$ No positivity rates for RT-PCR tests were reported until early April 2020. Because of the limited capacity for testing at the start of the pandemic, the Department of Health imposed strict protocols in order to ration testing resources while ramping up testing capacity. Most tests were conducted for individuals in urban areas, where the incidence was highest. $^{19}$

\section{CONCLUSIONS}

At the start of the COVID-19 pandemic, the country's initial response lacked organizational preparedness to counter the public health threat. The Philippines' disease surveillance system could conduct contact tracing, but this was overwhelmed in the early phases of outbreak response. Similarly, in February, only one laboratory could conduct reverse transcriptase polymerase chain reaction (RT-PCR) testing, so the country could not rapidly deploy extensive laboratory testing for infected cases. In addition, the primary care system of the Philippines did not serve as a primary line of defence, as people went straight to hospitals in urban areas, overwhelming critical care capacity in the early stages of the COVID-19 pandemic.

In response to the early phase of the pandemic, the Government of the Philippines implemented travel restrictions, community quarantine, risk communication and testing; however, the slow ramping up of capacities particularly on testing contributed to unbridled disease transmission. By 15 October, the number of confirmed cases had exponentially grown to 340,000 of which $13.8 \%$ were deemed active. ${ }^{11}$ The lack of pandemic preparedness had left the country poorly defended against the new virus and its devastating effects. Investing diligently and consistently in pandemic prepared- ness, surveillance and testing capacity in particular is a lesson that the Philippines and other LMICs should learn from COVID-19.

\section{Acknowledgements}

None

\section{Conflict of interests}

None reported

\section{Funding}

Not applicable

\section{References}

1. Hospital beds (per 1,000 people). Washington, DC: World Bank; 2020. Available from: https://data.worldbank.org/indicator/ SH.MED.BEDS.ZS

2. World Bank open data. Washington, DC: World Bank; 2019. Available from: https://data.worldbank.org/, accessed 18 March 2020.

3. Phua J, Faruq MO, Kulkarni AP, Redjeki IS, Detleuxay K, Mendsaikhan $\mathrm{N}$, et al. Asian Analysis of Bed Capacity in Critical Care (ABC) Study Investigators, and the Asian Critical Care Clinical Trials Group. Critical care bed capacity in Asian countries and regions. Crit Care Med. 2020;48(5):654-62.

4. Human resources for health country profiles: Philippines. Manila: WHO Regional Office for the Western Pacific; 2013. Available from: https://iris.wpro.who.int/bitstream/handle/10665.1/7869/9789290616245_eng.pdf.

5. Dayrit M, Lagrada L, Picazo O, Pons M, Villaverde M. The Philippines health system review. New Delhi: WHO Regional Office for South-East Asia; 2018. Available from: https://apps.who.int/iris/ handle/10665/274579, accessed 28 August 2020.

6. McPherson M, Counahan M, Hall JL. Responding to Typhoon Haiyan in the Philippines. West Pac Surveill Response. 2015 Nov 6;6(Suppl1):1-4. doi:10.5365/wpsar.2015.6.4.HYN_026

7. Santiago JSS, Manuela WS Jr, Tan MLL, Sañez SK, Tong AZU. Of timelines and timeliness: lessons from typhoon Haiyan in early disaster response. Disasters. 2016;40(4):644-67.

8. Ventura RJ, Muhi E, de los Reyes VC, Sucaldito MN, Tayag E. A community-based gastroenteritis outbreak after typhoon Haiyan, Leyte, Philippines, 2013. West Pac Surveill Response. 2015;6(1):1-6.

9. Inter-Agency Task Force for the Management of Emerging Infectious Diseases. Resolution No. 01. Recommendations for the management of the novel coronavirus situation. Manila: Department of Health; 2020. Available from: https://www.officialgazette. gov.ph/downloads/2020/01jan/20200128-IATF-RESOLUTIONNO-1-RRD.pdf, accessed 3 June 2020.

10. February files. Manila: Civil Aeronautics Board; 2020. Available from: https://www.cab.gov.ph/announcements/category/february-16, accessed 19 March 2020. 
11. Updates of novel coronavirus disease (COVID-19). Manila: Department of Health; 2020. Available from: https://www.doh.gov. ph/2019-nCov, accessed 16 October 2020.

12. Marquez C. Palace releases temporary guidelines on Metro Manila community quarantine. Inquirer News. 14 March 2020. Available from: https://newsinfo.inquirer.net/1241790/palace-releases-temporary-guidelines-on-metro-manila-community-quarantine, accessed 18 April 2020.

13. Leung K, Wu JT, Liu D, Leung GM. First-wave COVID-19 transmissibility and severity in China outside Hubei after control measures, and second-wave scenario planning: a modelling impact assessment. Lancet. 2020;395(10233):1382-93.

14. Wilder-Smith A, Freedman DO. Isolation, quarantine, social distancing and community containment: pivotal role for old-style public health measures in the novel coronavirus (2019-nCoV) outbreak. J Travel Med. 2020;27(2).

15. Digital 2020: The Philippines. DataReportal - global digital insights. Available from: https://datareportal.com/reports/digital2020-philippines, accessed 28 August 2020.
16. Nicomedes CJC, Avila RMA. An analysis on the panic during COVID-19 pandemic through an online form. J Affect Disord. 2020;276:14-22.

17. Lau LL, Hung N, Go DJ, Ferma J, Choi M, Dodd W, et al. Knowledge, attitudes and practices of COVID-19 among income-poor households in the Philippines: A cross-sectional study. J Glob Health. 2020;10(1).

18. Nuevo CE, Sigua JA, Boxshall M. Wee Co PA, Yap ME. Scaling up capacity for COVID-19 testing in the Philippines. Coronavirus (COVID-19) blog posts collection. London: BMJ Journals; 2020. Available from: https://blogs.bmj.com/bmjgh/2020/06/05/scaling-up-capacity-for-covid-19-testing-in-the-philippines/, accessed 28 August 2020.

19. Decision tool for 2019 novel coronavirus acute respiratory disease (2019-nCoV ARD) health event as of January 30, 2020. Manila: Department of Health; 2020. Available from: https://www.doh. gov.ph/sites/default/files/health-update/COVID-19-Advisory-No2. pdf, accessed 28 August 2020. 